\title{
CORRESPONDÊNCIA DE OCTÁVIO DA COSTA EDUARDO PARA MELVILLE HERSKOVITS (1943/1944)
}

\section{CORRESPONDENCE OF OCTÁVIO DA COSTA EDUARDO TO MELVILLE HERSKOVITS (1943/1944)}

\author{
Sergio F. Ferretti*
}

\section{Introdução}

Em meados da década de 1940, um jovem paulista que cursava pós-graduação em antropologia nos Estados Unidos foi encaminhado ao Maranhão para realizar pesquisas sobre o negro e as religiões afro-maranhenses e elaborar uma tese sobre o assunto. Esse trabalho, elogiado por especialistas como Roger Bastide, foi pouco divulgado, não tendo sido traduzido até agora. Recentemente, o antropólogo paulista Rodrigo Ramassote, realizando estudos de pós-doutorado, localizou nos arquivos da Northwestern University, nos EUA, a correspondência redigida entre o pesquisador e seu orientador, a qual vamos comentar aqui. A correspondência está sendo publicada neste mesmo número da Revista.
Dr. Octávio da Costa Eduardo é um pesquisador longevo, estando próximo de completar cem anos de idade. Desde a década de 1980 até hoje, quando possivel, tenho mantido contato com ele em São Paulo, especialmente para conversar sobre a pesquisa que realizou durante oito meses no Maranhão entre 1943 e 1944, na época do pleno funcionamento da Casa das Minas. Dessa pesquisa, resultou sua tese de doutorado, The Negro in Northern Brazil: a study in acculturation, orientada pelo professor Melville Herskovits. 0 orientador, autor e divulgador da teoria da aculturação, era o mais importante estudioso e conhecedor da cultura afro-americana. Discípulo de Franz Boas, publicou grande número de livros e artigos sobre Suriname, Benin (Daomé), Brasil, Haiti, Gana, Nigéria, Trindade, o negro nos EUA, etc.

\footnotetext{
* Doutor em antropologia, professor da Pós-Graduação em Ciências Sociais da Universidade Federal do Maranhão (UFMA/São Luís/MA/BR), bolsista de produtividade em pesquisa do CNPQ - professor emérito da UFMA - realiza pesquisas e publica trabalhos sobre cultura popular, religiões afro-brasileiras, tambor de crioula e tambor de mina do Maranhão. ferrettisf@gmail.com.
} 
Costa Eduardo nasceu em 1919 no interior de São Paulo, em família de classe média. Conta que o pai tinha um cartório e resolveu abrir uma firma de exportação de café em Santos. Com a crise de 1929, uma saca de café que valia cem passou a valer dez na moeda da época. Ele lamenta que a família tenha ficado na miséria e tenha perdido o equivalente a cerca de um milhão de dólares. Nos anos de 1930, 0ctávio Eduardo foi para a capital e iniciou curso de Direto na USP. Constatando que os advogados necessitam conhecer a sociedade e lendo nos jornais notícia sobre a recém-criada Escola Livre de Sociologia e Política de São Paulo (ELSP), resolveu estudar Ciências Sociais. Mais tarde, concluiu o curso de Direito, mas, em vez de advogado, tornou-se antropólogo, professor e pesquisador. Matriculou-se na ELSP, onde teve grandes professores, entre os quais Donald Pierson. Este, nos anos 1940 e 1950, lecionou e realizou muitos trabalhos na ELSP, organizando a pós-graduação, orientando estudantes, dirigindo pesquisas, publicando e traduzindo importantes obras de sociólogos e antropólogos de língua inglesa.

A ELSP desenvolveu estudos de sociologia e pesquisa de campo. Durante a Segunda Grande Guerra Mundial, o antropólogo inglês Radcliffe-Brown passou cerca de dois anos no Brasil como adido cultural. Costa Eduardo o conheceu na ELSP, conversou muito com ele e, à época, estava muito interessado em estudar sociologia. Pierson sugeriu e indicou o antropólogo paulista para pós-graduação em Chicago e o encaminhou a americanos que trabalhavam no Brasil com pesquisas de mercado e de opinião.

Em 1940, quando estudante de Ciências Sociais, participou de uma grande pesquisa de opinião no Brasil organizada por ameri- canos. Estavam interessados em saber se os brasileiros ficariam ao lado dos americanos ou dos alemães em uma possível entrada do Brasil na Segunda Guerra Mundial. À época, o país se aproximava mais do Eixo do que dos EUA. A pesquisa mostrou que os brasileiros ficariam com os americanos. Durante essa pesquisa, Costa Eduardo viajou de navio por vários estados do Brasil e começou a conhecer o país. Desde 1940, passou a se interessar por pesquisas de opinião e de mercado, área que, mais tarde, se tornou sua principal ocupação, e da qual foi um dos pioneiros no Brasil. Em 1962, trabalhou com técnicas de amostragem no meio rural, o que era novidade nas pesquisas de opinião.

Costa Eduardo trabalhou na Secretaria Municipal de Cultura, então dirigida por Mário de Andrade, cujo diretor do Serviço de Documentação do Estado era Sergio Milliet. Em 1941, foi para os Estados Unidos realizar estudos de antropologia orientado por Melville Herskovits. Por sugestão do orientador, o jovem antropólogo foi realizar pesquisas de campo no Maranhão. Em certas regiões do Brasil, como Salvador, Rio de Janeiro, Recife e Porto Alegre, desde a década de 1930 (e mesmo antes), foram realizadas e divulgadas pesquisas sobre as religiões afro-brasileiras. No Maranhão, só a partir de 1947/48 surgiram os primeiros resultados de pesquisas sobre as religiões de origens africanas, realizadas por Costa Eduardo, Manuel Nunes Pereira pela Missão de Pesquisas Folclóricas.

\section{Pesquisas anteriores ao trabalho de Cos- ta Eduardo}

No Maranhão, a Casa das Minas, em fins da década de 1930, foi visitada pelo etnógrafo e historiador português Edmundo Correa 
Lopes, que publicou artigos enfatizando a importância dessa região, para onde julga que deveriam convergir interesses dos estudiosos das religiões afro-brasileiras. 0 pesquisador português considera que o vasto patrimônio musical, coreográfico, psicológico, histórico e folclórico daquele terreiro jeje, apesar do que ele tenha coletado pessoalmente, nunca venha a ter o estudo que merece. Nunes Pereira comenta a importância desse e de outros escritos de Lopes ${ }^{1}$, cujos trabalhos foram publicados, principalmente, em revistas e livros em Portugal.

A Missão de Pesquisas Folclóricas, organizada por Mário de Andrade para realizar pesquisas e documentar manifestações religiosas e folclóricas no Nordeste do Brasil, passou uma semana no Maranhão em 1938 e documentou toques de tambor de crioula e de tambor de mina na casa de dona Maximiliana, no bairro de João Paulo. Os resultados dessa pesquisa começaram a ser divulgados em 1948, continuam sendo publicados e constituem documentos pioneiros sobre religião e cultura popular no Nordeste.

Em 1943, Nunes Pereira apresentou, na Sociedade Brasileira de Antropologia e Etnologia (SBAE), fundada e dirigida pelo Prof. Arthur Ramos e que funcionava na Faculdade Nacional de Filosofia da Universidade do Brasil, no Rio de Janeiro, a conferência "Negros Mina Jejes no Maranhão”. 0 trabalho foi publicado pela mesma sociedade, em 1947, com o título A Casa das Minas, com prefácio de Arthur Ramos. Por ocasião da conferência, Ramos chamou atenção para o ineditismo da pesquisa e para a prioridade dos estudos brasileiros na apreciação das influências negras no Maranhão (AZEREDO, 1986).

No prefácio, Ramos mostra que o autor identificava a existência de sobrevivências daomeanas e destaca o fato de que, em outras regiões do país, os traços daomeanos são incorporados ao sincretismo jejenagô. No Maranhão, Nunes Pereira estava demonstrando a existência de um culto de influência daomeana institucionalizado. Ramos explica que, num seminário na Northwestern University, em 1941, havia sugerido ao professor Herskovits uma viagem de pesquisa de ambos ao Maranhão, que infelizmente não foi realizada, e diz que um jovem estudante de Pierson e Herskovits, Octávio da Costa Eduardo, realizara pesquisas no Maranhão em 1943/44, pesquisas estas cujo resultado aguardava publicação. Ramos comenta também que as pesquisas de Nunes Pereira datam de 1942 e foram apresentadas em 1943 na SBAE, informando que o autor apresenta aspectos religiosos da Casa das Minas, identifica termos de parentescos daomeanos e nomes de entidades cultuadas. Por fim, Ramos considera que o trabalho de Nunes Pereira, embora classificado modestamente pelo próprio autor como um depoimento, vem preencher uma lacuna nos estudos do negro no Brasil.

Com formação acadêmica em Medicina Veterinária, Nunes Pereira informa que, na infância, entrara em contato com a religião da Casa das Minas, pois sua mãe e uma tia eram antigas dançantes da Casa

1. Edmundo Correia Lopes (1945) publicou um comentário filológico sobre a Obra nova de lingua geral de mina, de Antônio Costa Peixoto, segundo manuscrito localizado na Biblioteca Pública de Évora, escrito em Minas Gerais em 1741 e publicado em Lisboa por Luís Silveira, em 1943. Trata-se de vocabulário usado pelos escravos daomeanos no Brasil. Yeda Pessoa de Castro (1980) considera que "é o documento linguístico mais interessante que temos do tempo da escravidão". 
e, quando menino, foi por elas oferecido à proteção de um vodum, afırmando que isto facilitou muitas das informações que conseguiu. Destaca a importância da velha mãe Andresa, que então chefiava a Casa. Seu trabalho foi comentado e elogiado pelo sociólogo Roger Bastide, que lhe solicitou maiores informações sobre a mitologia. A segunda edição ampliada do livro só foi publicada em 1979. Nunes Pereira (1979, p.22), considera que a Casa das Minas “é uma sociedade africana transplantada para o Brasil" e comenta aspectos de sua organização, como coesão familiar, terminologia de parentesco, regime matriarcal e elementos da mitologia. 0 autor nega a presença significativa de elementos indígenas, católicos ou espíritas e propõe a existência de um sincretismo mina, jeje, nagô e muçulmi. Bastide, em muitos trabalhos sobre religiões afro-brasileiras, divulgou observações de Nunes Pereira e de Costa Eduardo sobre a Casa das Minas.

\section{Correspondência entre Costa Eduardo e Herskovits}

Antes de viajar para os Estados Unidos, Costa Eduardo procurou dona Heloísa Alberto Torres, diretora do Museu Nacional, que, à época, supervisionava pesquisas científicas no interior do país e correspondia-se com diversos pesquisadores estrangeiros que vieram realizar pesquisas no Brasil. Dona Heloísa respondeu mensagem de Herskovits explicando que Costa Eduardo poderia ter a pesquisa vinculada ao Museu Nacional, deu a Eduardo cartas para autoridades, como Paulo Ramos, interventor no Maranhão, e solicitou redução no preço das passagens aéreas. Mais tarde, Costa Eduardo constatou que tinha sido convocado para a Guerra quando estava estudando nos EUA. Herskovits falou com Heloísa, que foi ao Ministro da Guerra, e o General Dutra, autorizou a liberação do antropólogo paulista.

Em 1941, Costa Eduardo foi para os Estados Unidos, na época em que Herskovits veio realizar pesquisas no Brasil. Em depoimento pessoal, o antropólogo paulista disse-nos que, a partir do currículo que apresentou ao solicitar bolsa da Fundação Rockfeller, Herskovits o escolheu para ser seu orientando e para realizar pesquisas sobre o negro. Costa Eduardo foi para a Northwestern University, em Evanston, município próximo a Chicago, que está entre as vinte mais famosas universidades norte-americanas. Cursou disciplinas com Herskovits, que era um grande professor, entre outros docentes. Cursou antropologia e outras disciplinas com Willian Bascom. Nas férias, foi para a Universidade de Fisk, que era uma universidade de negros e para negros.

Herskovits estava interessado em estudar o encontro de culturas e a aculturação no Novo Mundo. Informou a Costa Eduardo que o Maranhão era uma região para onde foi um grande número de escravos e que ainda não tinha sido estudada. Em 1943, antes de vir ao Maranhão, Costa Eduardo redigiu dissertação de mestrado sobre a natureza e o papel da religião na África Ocidental, o que fez com que se aprofundasse nesse tema. Herskovits o encarregou de realizar pesquisas sobre o negro no Maranhão, onde Costa Eduardo permaneceu por oito meses entre 1943 e 1944. Nesse período, o orientando escreveu e recebeu diversas cartas dando notícias, discutindo dificuldades e solicitando orientações. Por correspondência, Herskovits acompanhou e deu muitas sugestões ao jovem pesquisador, que tinha grande facilidade em observar e realizar entrevistas. Eduardo des- 
crevia e comentava com o orientador as festas de terreiros com muitos detalhes e informações sobre os rituais e as divindades cultuadas.

A correspondência entre Costa Eduardo e seu orientador foi redigida durante esse período. 0 orientando presta contas do trabalho de campo, das observações realizadas e pede sugestões. 0 orientador comenta e faz indagações. 0 orientando relata problemas de saúde, problemas financeiros, dificuldades enfrentadas na pesquisa de campo e os discute com o orientador. Transmite também informações sobre fatos de sua vida pessoal, contando, por exemplo, que na primeira viagem de retorno ao Brasil havia ficado noivo e tinha pretensões de se casar, mas que isso não iria prejudicar seus trabalhos de pesquisa ${ }^{2}$. Manda sempre lembranças à esposa e à filha de Herskovits, demonstrando a relação de intimidade que estabeleceu com o orientador e sua família.

As cartas de Costa Eduardo constituem praticamente um diário de campo e apresentam muitas informações em primeira mão sobre as circunstâncias da pesquisa. Nelas, o estudante relata suas primeiras impressões sobre as religiões de origem africana no Maranhão; discorre sobre contatos com mãe Andresa e outras vodunsis da Casa das Minas e da Casa de Nagô; descreve o trabalho de campo em São Luís e em Santo Antônio dos Pretos, em Codó, no interior do Estado; e demonstra, na prática, como realizar o trabalho de campo. Essa correspondência representa um bom modelo de relações entre o orientador e o estudante na pesquisa de antropologia das populações afro-brasileiras.
A esse respeito, são importantes e oportunas as observações de Marcio Goldman (2003, p. 469): “Na antropologia, a leitura das notas e dos cadernos de campo, a imersão no material coletado e, principalmente, a própria escrita etnográfica revivem o trabalho de campo, fazem com que sejamos afetados de novo".

Costa Eduardo nos disse que Herskovits era um grande professor, que ensinava e tornava as coisas muito mais claras, dava aulas brilhantes sobre teorias e sobre práticas de pesquisa. Comentou que Herskovits nasceu em 1895 e que morreu cedo, com 67 anos. Segundo o antropólogo, Herskovits foi um dos principais alunos de Franz Boas, que organizou e dirigiu os estudos de antropologia nos Estados Unidos na primeira metade do século XX. Costa Eduardo comenta o conceito de Herskovits de "enculturação", que diferencia de "socialização”. Segundo ele, a enculturação explica a tenacidade de certas instituições - como as religiosas - na sociedade. Estamos sujeitos à nossa cultura desde o princípio da vida. 0 ser humano, no início, só aprende, só imita, e isso provoca a enculturação. 0 processo de enculturação explica por que as crenças africanas foram mantidas e preservadas durante tanto tempo através do ensino das mães aos filhos.

Em 1945, Costa Eduardo tornou-se o primeiro brasileiro que concluiu $\mathrm{PhD}$ em antropologia nos Estados Unidos com a tese The Negro in Northern Brazil: A study in acculturation, publicada em Nova York, em 1948. Em 1950, Roger Bastide escreveu, na revista Sociologia, da ELSP, uma resenha elogiosa sobre o trabalho de Cos-

2. Dona Maria Eugênia, com quem Costa Eduardo se casou ao voltar do exterior e com quem conviveu por mais de 65 anos, faleceu em fins de 2011. No início de 2012, quando o visitamos, ele nos disse que estava muito deprimido com essa perda. 
ta Eduardo com o método da observação participante, relativo a aspectos históricos, econômicos, familiares e religiosos de pequenas comunidades negras em São Luís e Codó, no Maranhão.

$\mathrm{Na}$ correspondência com o orientador, Costa Eduardo menciona que, no Maranhão, tinha alguns grandes amigos, como o Dr. Antônio Teixeira Leite, chefe do setor de Traumatologia do Hospital, que o recebia em sua casa. Contou-nos que ele era casado com dona Ondina e tinha duas filhas. Antônio Teixeira representava, para ele, uma família que o apoiava no Maranhão. Disse que foi também amigo de Dr. Cesário Veras e de outros maranhenses. Lembrou também do encontro que tinha todos os dias com intelectuais na praça principal da cidade. Outra pessoa muito amiga era uma jamaicana, dona da pensão em que residia, com quem conversava em inglês. Na Casa das Minas disse que ficou muito amigo do tocador Maneco.

Herskovits sugeriu que seu orientando fizesse um estudo comparativo sobre o negro na capital e no interior do Estado. Em conversas com o orientador e contatos locais, Costa Eduardo resolveu estudar uma comunidade negra no meio rural. Ele diz que foi muito bem recebido em Santo Antônio dos Pretos, no interior do município de Codó, onde conheceu vários amigos. Ia caçar, com eles, veados grandes na mata. Para chegar lá, andou um dia inteiro a cavalo de Codó a Santo Antônio, pois felizmente, quando rapaz, aprendera a andar cavalo na fazenda de um amigo. Passou dez dias na cidade de Codó e dois meses em Santo Antônio dos Pretos. Quando foi se despedir, perguntou quanto deveria pagar pelas despesas de hospedagem e alimentação e o dono da casa disse que não devia nada, pois ele era um deles. Em fins de abril, Costa Eduardo re- tornou por quinze dias a Codó. Ele diz que, no passado, chegaram a existir três terreiros na cidade, mas todos haviam sido fechados pela polícia. Mesmo assim, organizaram na praça um "brinquedo" de tambor para ele em que compareceram umas dez dançantes, com cerca de 250 pessoas assistindo. Começou no início da tarde de sábado e durou até a tarde do domingo.

Costa Eduardo recorda que, assim que chegou a São Luís, Dr. Antônio Lopes o acompanhou em algumas caminhadas aos terreiros e deu várias informações sobre o negro no Maranhão. Sugeriu que ele fosse também realizar pesquisas em Codó, onde havia muitos negros. Herskovits mandara-o a São Luís para estudar a Casa das Minas e a Casa de Nagô, mas algumas vezes ele ia também assistir toques de pajelança. Foi umas quatro vezes, e afirma que publicou artigo sobre pajelança numa revista americana (que ainda não conseguimos localizar).

0 antropólogo lembra ainda de Dudu, da Casa de Nagô, que diz ser uma pessoa fascinante, alegre, cheia de vida, conversadora. Mãe Andresa, filha de Poliboji, era como uma rainha da Inglaterra: delicada e amorosa. Essas observações estão de acordo com o que se diz até hoje sobre essas duas importantes mães de santo, matriarcas do tambor de mina do Maranhão. Costa Eduardo nos falou que, em 1954, foi ao Pará fazer uma pesquisa para a Shell, passou por São Luís e visitou mãe Andresa em seu leito de morte. Ela o reconheceu e ficou emocionada. Estava muito abatida, mas perfeitamente lúcida, tendo falecido poucos meses depois.

Costa Eduardo passou oito meses no Maranhão, de inícios de novembro de 1943 a fins de junho de 1944, sendo dois meses em Codó, no povoado de Santo Antônio dos Pretos. Nesse período, tinha 24/25 anos, e mãe Andresa tinha cerca de 90 anos. Tendo 
em vista o fechamento e a reserva dos participantes da Casa das Minas, que o pesquisador comenta em algumas cartas, em pouco tempo conseguiu informações fundamentais para seu trabalho. Além de Costa Eduardo estar bem treinado e ter experiência como etnólogo, talvez o fato de ser um jovem pesquisador vindo de fora tenha estimulado as velhas vodunsis da Casa a adotá-lo como filho e transmitir-lhe informações sobre detalhes de sua religião que muito o interessavam. Na Carta $n^{\circ}$ 6, de 10 de dezembro, ao escrever sobre características das famílias de voduns, Eduardo afirma: "Só aos poucos fui obtendo estas informações e confessolhe que não foi fácil. Os pretos são hábeis em esquivar-se a perguntas; simplesmente dizem que não sabem”.

Nas cartas, Costa Eduardo descreve os rituais que assistiu durante sua estada no Maranhão. Baseado em observações de campo e em entrevistas, principalmente com mãe Andresa, ele apresenta ao orientador informações sobre a ausência de Legba ou Exu na Casa das Minas, sobre o ritual para que Legba não viesse atrapalhar o brinquedo e sobre a ausência de feitiços nas encruzilhadas (Cartas 07; 08 e 09). Apresenta também observações sobre o sincretismo entre voduns e santos católicos (Carta 07), sobre a iniciação na casa jeje (Carta 07), sobre rituais fúnebres (Carta 08), sobre tambor de pagamento (Carta 09) e sobre etapas que antecedem as festas grandes (Carta 10); documentos sobre origens dos escravos (Cartas 05; 08; 09; 12; 13); e diferenças entre tambor de mina e candomblé (Carta 18); entre tambor de mina, de cura e de pajelança (Carta 04) e entre tambor de mina e tambor de crioula (Carta 17). 0 antropólogo escreve que as festas da Casa das Minas, nas quais compareciam entre 15 e 18 voduns, eram assistidas por cerca de uma centena de pessoas (Carta 06), e enumera as várias fases da festa do Divino no terreiro (Carta 17), falando sobre dificuldades enfrentadas no trabalho de campo (Carta 05), apresentando um panorama sobre os terreiros de São Luís (Carta 04 e Carta 07) e muitas outras informações importantes.

Costa Eduardo comenta com o orientador as características dos toquenos, os voduns meninos que vêm na frente e chamam os outros, e das tobossis, entidades femininas infantis que vinham três vezes ao ano, recebidas antes dos voduns pelas vodunsis gonjaís (Carta 09). Lembra que conheceu tais entidades e em sua tese (Eduardo, 1948) transmite o nome de nove das dezoito tobossis de que teve notícias. 0 antropólogo paulista conseguiu detalhes importantes sobre as divindades cultuadas na casa jeje. Apresenta com precisão o nome dos principais voduns, relações de parentesco, características do transe das vodunsis (Carta 06), regras de cortesia e o papel dos toquenos e das tobossis, que deve ter conseguido com cuidadosas observações e entrevistas prolongadas com as vodunsis e os tocadores, demonstrando o excelente trabalho etnográfico que realizou.

As informações de Costa Eduardo sobre os nomes dos voduns da família real ou de Davisse na Casa das Minas permitiram que fossem identificadas por Herskovits relações entre voduns da casa com o culto dos ancestrais da família real do Daomé até fins do século XVIII, fato que ainda não fora identificado no Novo Mundo. Na carta ${ }^{\circ}$ 8, de 18 de janeiro de 1944, Costa Eduardo escreve: "Seus esclarecimentos sobre os nomes das divindades jêjes aqui cultuadas caíram como uma bomba. Eu, realmente, estava sem uma explicação para aqueles nomes que eu nunca tinha ouvido antes”. Comenta que, à época, a seu ver, as vodun- 
sis da Casa das Minas não tinham conhecimento das relações entre os voduns que cultuavam e ancestrais da família real, mas diz que os fundadores deviam saber.

0 fotógrafo e etnógrafo francês Pierre Verger, que visitou e documentou o Maranhão em 1948, afirma, em artigo de 1952 (republicado em 1990), que também conseguiu de mãe Andresa nomes de voduns e, mais tarde, identificou grande número destes voduns com membros da família real do Daomé. A partir dessas pesquisas, Verger explica que a fundadora da Casa das Minas foi a rainha Nã Agontime, mãe do Rei Guezo, que foi vendida como escrava e, assim, chegou ao Maranhão. Até então, afırmava-se que a fundadora da Casa fora Maria Jesuína, que teria vindo como escrava de contrabando. Após a divulgação, em São Luís, da hipótese de Verger, a partir de meados da década de 1980, pessoas da Casa passaram a dizer que sabiam que a fundadora era uma rainha, mas isso não era comentado por razões de segurança. No relatório final de um colóquio sobre religiões de origens africanas organizado em São Luís pela Organização das Nações Unidas para Educação, Ciência e Cultura (UNESCO) em 1985, lê-se:

São Luís e a experiência original da Casa das Minas, fundada no Brasil pela Rainha Agontimé, mãe do Rei Ghezo, condenada à deportação a seguir a um ajuste de contas no seio da família real, antes que o seu filho acedesse ao trono do Danxomê em 1818 e lançasse uma vasta operação em busca de sua mãe. A comunidade da Casa das Minas, com base na família, continua a tradição real de Zomadonu [...] (UNESCO, 1986, p. 34).
Costa Eduardo conseguiu também informações sobre nomes de muitas entidades cultuadas na Casa de Nagô. Na Casa das Minas, cada pessoa costuma ter um nome jeje dado pelos voduns. É interessante Costa Eduardo mencionar que recebeu dos voduns o nome africano de Bosso Hodokhuê (Carta $n^{\circ} 15$ de 20/04/44) e explicar seu significado dizendo que ele é de Dambirá, filho de Poliboji, por causa da velha mãe Andresa, e que é filho da Casa. Esse detalhe demonstra o nível das boas relações entre o pesquisador e os participantes do grupo de culto. Não temos conhecimento de outro pesquisador da Casa das Minas que tenha recebido dos voduns um nome africano.

Na correspondência, Costa Eduardo diversas vezes fala com o orientador sobre a beleza dos cânticos e das danças do tambor de mina. Considera que os músicos são excelentes, e afirma ser imprescindível conseguir algumas gravações. 0 antropólogo escreve que ficou encantado com a música e com o ritmo dos toques e tentou, com dona Heloísa e outros, conseguir cilindros para gravar alguns toque (Carta 06; Carta 09). Ele encaminha ao orientador algumas fotos de rituais na Casa das Minas (Carta 17).

Apesar de dificuldades relacionadas com o período da guerra, Costa Eduardo conseguiu algumas pequenas fotografias da Casa das Minas. Nessa correspondência do arquivo de Herskovits na Northwestern University foram encontradas algumas fotos da Casa das Minas que ele remeteu ao orientador ${ }^{3}$.

0 antropólogo explica que as canções e danças constituem um grande teatro e

3. Publicamos, com a correspondência, três dessas fotos que estão em melhores condições. Em entrevista, Dr. Octávio uma vez nos mostrou uma coleção de cerca de vinte pequenas fotos tiradas em rituais da Casa das Minas. Disse que tinha poucas, pois, durante a guerra, era muito difícil conseguir material fotográfico no Maranhão. 
comenta seu desapontamento por conta do seguinte fato: conseguira, com muito esforço, comprar alguns discos e arranjar aparelho e técnico para as gravações, e só faltava a autorização. À noite, houve um toque e ele pediu autorização a Poliboji, vodum da mãe do terreiro. Este lhe respondeu, de forma amável, mas firme, que o velho, Dadarrô, não queria que se gravassem os ritmos dos tambores. Costa Eduardo diz que foi uma recusa que ele não esperava, porque era considerado filho da casa, e explica que a música jeje é impressionante e lamenta não ter recebido autorização para gravá-la. Queria fazer as gravações porque desejava ter uma lembrança delas, por gostar da música, e queria que seu professor também as ouvisse (Carta $\mathrm{n}^{\circ}$ 9).

As descrições que apresenta, pouco tempo após sua chegada no Maranhão, sobre o toque dos tambores, após assistir apenas a primeira festa na Casa das Minas, são exatas e minuciosas, demonstrando agudo senso de observação. A referência aos nomes dos voduns e a descrição da festa que assistiu como recém-chegado é perfeita, como também, mais tarde, a descrição da Festa de Pagamento aos tocadores e dos diferentes momentos da Festa do Divino.

Quando retornou ao Brasil, foi trabalhar na Escola Livre de Sociologia e Política, onde lecionou e ocupou diversos cargos pedagógicos e administrativos. Casou-se, constituiu família, teve filhos e continuou a correspondência com Herskovits. Nas décadas de 1940 e 1950, além de outras atividades, Costa Eduardo realizou pesquisas e publicou trabalhos sobre religiões afro-maranhenses e outros assuntos, como pesquisas de mercado e de opinião, que começaram a lhe interessar. Em fins de 1940, ingressou numa pesquisa de opinião patrocinada pela ESSO e aprendeu a realizar amostras probabilísticas que não eram conhecidas no Brasil. Passou, então, a participar de diversas pesquisas de opinião e de mercado.

Assim dedicou-se a dar aulas e realizar pesquisas. Como primeiro antropólogo que concluiu doutorado nos Estados Unidos, Costa Eduardo participou de diversas bancas de teses de doutorado e de concursos para professor, como de Florestan Fernandes, de Maria Isaura Pereira de Queiroz, de Egon Schaden, de Ruy Coelho e de outros Contou-nos que Florestan Fernandes era pessoa brilhante, mas intransigente e difícil, e que foi seu aluno num curso sobre o negro no Novo Mundo. Costa Eduardo esteve nas bancas de mestrado e de livre-docência de Fernandes e disse que foi também professor de Sergio Buarque de Holanda. Segundo o pesquisador, Assis Chateaubriand deu apoio à ELSP. Ele fala de Ciro Berlinck, que foi diretor da ELSP e era seu amigo, e de Darcy Ribeiro, que também estudou na ELSP. Juarez Brandão Lopes foi estudar nos Estados Unidos, mandado e mantido pela Escola, e era a esperança de sua continuidade. Porém, como a instituição pagava mal, acabou indo para a USP e para o CEBRAP. Costa Eduardo participou do Conselho da escola e deu aulas até se aposentar, nos anos de 1970.

Como o trabalho na ELSP não era bem remunerado, o antropólogo teve que assumir diversos cargos administrativos na Escola - a ELSP era mantida com o apoio da Prefeitura de São Paulo e com outras parcerias, mas os recursos eram limitados. Desde 1940, Costa Eduardo vinha participando de pesquisas de mercado e de opinião, constatando que essa área era mais bem remunerada e dinâmica. Tendo que manter a família e os filhos, e sendo de família pobre, precisava ganhar dinheiro. Passou a se dedicar mais à pesquisa de mercado e pu- 
blicou poucos trabalhos sobre religiões afro -brasileiras. Seu trabalho de pesquisa sobre os negros no Maranhão, até hoje, não foi traduzido em português. Daí o interesse da divulgação desta correspondência. De fato, a correspondência de Costa Eduardo com Herskovits representa praticamente o diário de campo da pesquisa, que infelizmente até hoje ele não divulgou ${ }^{4}$.

Durante e depois da Segunda Guerra, a pesquisa de mercado e de opinião se desenvolveu muito no Brasil, ampliando-se com o aumento da industrialização. Em 1955, Costa Eduardo envolveu-se mais com a área e fundou o Instituto Nacional de Pesquisa e Estudos Sociais e Econômicos (INESE), um dos mais antigos institutos de pesquisa de opinião e de mercado do Brasil, onde trabalhou até se aposentar. À época, no Brasil, só existia, o Instituto Brasileiro de Opinião e Estatística (IBOPE), fundado em 1942. Costa Eduardo se tornou um dos pioneiros desse ramo no País. A partir de então, continuou trabalhando na ELSP e passou a se dedicar mais ao estudo e a pesquisas de mercado. Os estudos sobre o negro e as religiões afro-brasileiras no Maranhão, de que ele foi um dos iniciadores, ficou em segundo plano, e o pesquisador deixou de publicar trabalhos nessa área.

Em 2010, em uma das vezes em que estivemos com Costa Eduardo, ele disse que, em novembro, havia completado 89 anos e estava escrevendo para as Edições Paulinas um livro adaptado para crianças, ilustrado, que deveria ter três volumes, com histórias que ele coletou em Codó. A editora, até agora, publicou o primeiro volume, em que o autor aparece com o nome de Longevo (EDUARD0, 2010). Ele nos pareceu muito animado com isso. Mostrou também o texto de uma conferência que fez pelos 75 anos da ELSP. Disse que parte de sua biblioteca e arquivo deverá ser doada para a ELSP. Uma parte da biblioteca deverá ficar para os netos, sobretudo para uma neta que é desenhista industrial e, atualmente, é a intelectual da família.

Ele nos disse que tem planos de escrever ainda três livros: o primeiro é um dicionário sobre pesquisa de mercado com 3 mil palavras, das quais ele já redigiu mais de um terço e parou por conta de ter enfrentado uma depressão, mas que pretende continuar. Já tem tudo fichado e, quando pode, escreve cerca de três verbetes por dia; o segundo é traduzir e ampliar o livro sobre a Casa das Minas, talvez precedido por estudo que ele fez para dissertação de mestrado sobre as religiões africanas e incluindo a publicação das histórias de animais para crianças, que coletou em Santo Antônio dos Pretos, em Codó; o terceiro será um livro sobre o material que coletou nas décadas de 1950 e 1960 numa grande pesquisa entre a Bahia e Pernambuco sobre o Vale do São Francisco, coordenada por Donald Pierson. Realizou pesquisas em Cabrobó, Pernambuco. Costa Eduardo disse que, quando tem condições, escreve sobre o material que coletou. Lamenta não ter publicado nada sobre a região e quer ver ainda se consegue redigir uma monografia em cima das muitas notas e da bibliografia que

4. Em conversa em sua residência em 21 de setembro de 1987, Dr. Octávio nos mostrou seu diário de campo e fotos de uma festa na Casa das Minas. Disse-nos que no campo tomava anotações numa caderneta pequena, depois passava para um caderno maior. Tinha boa letra no caderno. Batia tudo em fichas por assunto. Tem as fichas, os cadernos, as anotações e as poucas fotos. Disse também que mãe Andresa lhe ditava os cânticos da Casa e ainda conhecia alguns. 
possui e está consultando. Pretende publicar o estudo e, se conclui-lo, procurará um nome fictício para não identificar a cidade, como faziam os estudos de comunidade nas décadas de 1940 e 1950. Elogiou muito os estudos de comunidade de Charles Wagley.

\section{A tese de Octávio da Costa Eduardo}

Até fins da década de 1970, a Casa das Minas e o tambor de mina do Maranhão tiveram divulgação muito restrita, quase que exclusivamente entre poucos especialistas. Um ano após a primeira edição do livro de Nunes Pereira (1947), o antropólogo paulista Octávio da Costa Eduardo (1948) publicou nos Estados Unidos sua tese de doutorado, defendida em 1945 na Northwestern University, um valioso estudo sobre o negro no Maranhão, mas que, infelizmente, até hoje não foi traduzida para o português. Esses dois livros foram muito difundidos na obra de Roger Bastide, que, através deles, divulga o tambor de mina e fala sobre os rituais da Casa das Minas.

Costa Eduardo apresenta suas ideias de acordo com a teoria culturalista, difundida na antropologia norte-americana da época, principalmente por Melville Herskovits. Discute, entre outros conceitos, os de aculturação, mudança cultural, dinâmica cultural, sincretismo e foco cultural. A maior parte do trabalho é dedicada ao estudo da religião, mas apresenta elementos sobre a vida familiar e as relações econômicas. 0 autor caracteriza as casas de culto que conheceu, comparando as tradições religiosas no ambiente rural e urbano, concentrando-se, especialmente, na Casa das Minas; apresenta e comenta letras de cânticos, descreve danças, vestimentas, instrumentos musicais, práticas e rituais, divindades, mitologia, etc.; discorre so- bre o esquecimento de Legba, o trickster daomeano, hierarquias, tocadores e outros assuntos, e sobre os rituais de iniciação; distingue a categoria das vodunsi-he, que recebem um vodum, das vodunsi-hunjai ou gonjaí, que, além do vodum, recebem também uma entidade feminina infantil denominada tobossi; apresenta descrição do rito para feitura das gonjaí e se refere às nove então existentes; e identifica, entre as entidades cultuadas, membros do culto da família real do Daomé até fins do século XVIII, afirmando que os participantes do culto não tinham conhecimento muito claro deste fato (EDUARDO, 1948).

Costa Eduardo escreveu, em publicações brasileiras e estrangeiras, dois artigos referentes ao tambor de mina: um a respeito dos tocadores (1952) e outro sobre literatura oral em Codó (1951). Pelas valiosas informações etnográficas, seus trabalhos constituem a primeira tentativa de estudo científico dos cultos afro-maranhenses, hoje só acessíveis a poucos especialistas. Bastide (1950, p. 275), faz muitos elogios ao autor e considera que "o trabalho preenche uma lamentável lacuna no estudo dos negros do Maranhão" e que se trata de uma "monografia sobre diversos aspectos, históricos, econômicos, familiares e religiosos sobre a comunidade negra no Maranhão", (Bastide: 1950, p. 275) e espera que seja traduzida em breve.

Em sua tese, Costa Eduardo realiza estudo comparativo entre uma comunidade rural do Maranhão e grupos religiosos urbanos da capital. Em São Luís, estuda duas casas fundadas por africanos: a Casa de Nagô, de origem iorubana, e a Casa das Minas, estabelecida por daomeanos. Ele denomina as outras casas localizadas na periferia, de "iorubano derivadas", e casas ou grupos de pajelança ameríndia. 
A pesquisa destaca a preservação de modos de vida africanos e a aceitação de costumes e instituições europeias. 0 autor utiliza os conceitos defendidos por Herskovits de foco cultural e de província cultural do Velho Mundo e discute o problema geral de sobrevivências africanas entre os negros do Nordeste do Brasil, coletadas em duas comunidades nos meios urbano e rural, preocupando-se em saber qual dos meios facilitou mais o processo de aculturação.

Costa Eduardo estima que, em São Luís, a população girava em torno de 60 mil habitantes, dos quais cerca de 20 mil seriam descendentes de africanos. Ele informa que, à época da pesquisa, havia na cidade cerca de trinta casas de tambor de mina e pajelança. Em contraste com os negros rurais, os negros de São Luís mantiveram contatos contínuos com cidadãos brancos, cujos costumes diferiam dos seus em vários aspectos, como em elementos da vida econômica e familiar e das crenças religiosas e mágicas.

0 pesquisador apresenta dados do século XIX sobre origens da população escrava em inventários de São Luís e de Codó, constatando a sua procedência de diferentes regiões da África. Discutindo sobre origens e datas de entradas de africanos no Maranhão, percebe que o nome do rei Agonglo, que reinou no Daomé entre 1789 e 1797, era mencionado como uma das divindades adoradas pelo grupo, o que pode indicar que escravos daomeanos vieram para o Maranhão em fins do século XVIII ou inícios do XIX. Costa Eduardo recorda que o nome do rei Ghezo, que reinou no Daomé entre 1818 e 1858, era inteiramente desconhecido. Isso indica, segundo ele, que o grupo daomeano manteve então sua identidade por cerca de 150 anos (1948).

São apresentadas também muitas informações sobre o modo de vida das po- pulações rurais do interior, alimentação, relações familiares, trabalho cooperativo e o modo de vida dos negros urbanos como organização econômica e relações familiares. 0 pesquisador procura laços africanos na vida econômica e familiar dos negros no Maranhão, destacando o status da mulher e padrões do trabalho cooperativo em comparação com outras sociedades negras no Novo Mundo. Discute ainda características da vida familiar do negro dos meios urbanos e rurais do Maranhão, comparando-a com outras sociedades nas Américas e constatando que muitos homens mantêm duas famílias e que essas relações não são condenadas. 0 autor comenta relações entre netos e avós e relações de compadrio.

A maior parte do trabalho é dedicada ao estudo da religião dos negros nos meios rural e urbano. Costa Eduardo mostra que crenças e práticas africanas são mais institucionalmente preservadas em São Luís do que nas comunidades rurais. Há cerca de 70 ou 75 anos, foram estabelecidas em São Luís duas casas de culto, denominadas de tambor de mina: uma de origem daomeana e outra de origem iorubana, que são mais ortodoxas. 0 antropólogo denomina as demais de centros de culto "iorubano derivados". Outras casas que possuem elementos indígenas são chamadas de "pajelança” ou "cura".

Crenças católicas dos negros no Maranhão, como em outras partes do país, são largamente difundidas e têm muito em comum com crenças e práticas africanas, tendo facilitado a aceitação da religião católica e a difusão do sincretismo. Costa Eduardo relata uma série de crenças relacionadas com santos na vida cotidiana e descreve as diversas etapas da festa do Divino Espírito Santo e transcreve cânticos das caixeiras. Relata também os nomes das entidades recebidas pelos negros de Santo Antônio em 
Codó, explicando que Légua Boji de Codó é o Legba dos daomeanos. Ele apresenta características das casas de culto no meio rural, destacando a presença do mastro central e os instrumentos utilizados, entre os quais o berimbau, vestimentas, cânticos, possessão e danças. 0 autor transcreve diversos cânticos e práticas de magia, entre outros assuntos.

Passa então a descrever os centros de culto no meio urbano: suas características, formas de organização, rituais de iniciação e as divindades cultuadas na casa daomeana. Estas são identificadas como africanas e são organizadas em panteões. Apresenta comparação das divindades da Casa das Minas com as do Daomé, constatando que os nomes dos voduns da família de Davisse são os mesmos nomes dos reis do Daomé até 1797.

Costa Eduardo informa que alguns voduns, como Zomadonu, Agongono e Zaka, são conhecidos pelo termo Savalunu, nome da região ao norte do Daomé, o país Mahi, de onde são originários. Foi lá que começou o culto dos tohossu, espíritos de crianças anormais, liderado por Zomadonu. Passa a falar sobre a família dos voduns de Dambirá, o panteão da terra, chefiado por Akosi Sapatá. Depois, escreve sobre os voduns de Keviossô, que controlam a chuva, o trovão, o raio e as águas, e mostra diferenças entre o panteão da Casa das Minas e o panteão do Daomé. 0 autor acredita ser estranho que o culto de Legba, o trickster daomeano, aparentemente, foi perdido pelo grupo de São Luís que afirma ser cultuado na Casa de Nagô. Refere-se ao culto dos espíritos femininos infantis, as tobossis e diz o nome das que eram identificadas na época. Tendo sido orientado por Herskovits, que havia publicado livros sobre o Daomé e tendo redigido dissertação de mestrado sobre a natureza e as raizes das religiões da África Ocidental, Costa Eduardo demonstra em sua tese de doutorado que conhecia muito bem o assunto, desde suas fontes.

0 autor fala das divindades da Casa de Nagô que eram também chamadas de voduns. Os encantados com nomes brasileiros eram concebidos como nobres, e os espíritos indígenas eram chamados de caboclos. Acredita-se que todos vivem na encantaria e pertencem a diversas linhas. Voltando à Casa das Minas, informa-se que o grupo preservava a tradição de dar nomes privados às divindades e cita-se nomes privados dos voduns Poliboji e Agongono (EDUARDO, 1948) e de Xangô e Ogum na Casa de Nagô.

Costa Eduardo afırma ser uma tradição iorubana atribuir diferentes qualidades às divindades, como no cristianismo, onde também se dá diversos nomes aos santos. Ele descreve com detalhes os instrumentos, os cânticos e as danças dos voduns da Casa das Minas e sua ordem de apresentação; descreve os mesmos elementos na Casa de Nagô e nas casas de culto iorubano derivadas; refere-se às diferenças do transe com as tobossi e com os voduns; relata a festa do Tambor de Pagamento aos tocadores na Casa das Minas e na Casa de Nagô; menciona a cerimônia do jantar dos cachorros na Casa das Minas; explica os sacrifícios de animais oferecidos aos voduns realizados nas duas casas (que denomina de "ortodoxas"), sacrifícios estes que ocorrem principalmente em dezembro e janeiros e que só podem ser assistidos pelas iniciadas ou por membros qualificados do culto, como os tocadores.

0 antropólogo fala sobre os nomes africanos dos alimentos oferecidos aos voduns da Casa das Minas e da Casa de Nagô. Depois, expõe as diferentes práticas mágicas existentes nas classes baixas em São Luís e mencio- 
na algumas rezas utilizadas e rituais de pajelança com elementos indígenas e católicos. Faz comparações entre os rituais realizados no meio urbano, que considera como mais ricos em sobrevivências africanas, e explica possiveis razões de tais diferenças. Discorre também sobre o sincretismo existente entre tradições católicas e africanas.

No sexto capítulo, Costa Eduardo analisa crenças em almas e no anjo da guarda e os ritos fúnebres. Informa que as cerimônias fúnebres constituem o evento principal do ciclo de vida dos negros urbanos e rurais. As cerimônias mortuárias são marcadas por elementos rituais europeus e outros de origem africana. 0 autor descreve rituais fúnebres no meio rural e na Casa das Minas. No sétimo e último capítulo, apresenta um resumo sobre a aculturação dos negros no Maranhão.

Pelo contato de Costa Eduardo com antigas vodunsis, especialmente com mãe Andresa e com Dudu da Casa de Nagô, pela acuidade das observações e pelas informações etnográficas que apresenta, seu trabalho é de grande importância, sendo a primeira pesquisa antropológica sobre os cultos afro-maranhenses. É igualmente importante a preocupação do autor em analisar elementos econômicos e a vida familiar ao lado da análise da religião. Como outros trabalhos de antropologia, os estudos de Costa Eduardo utilizam os conceitos e orientação teórica vigentes na época e adotados então por muitos estudiosos, como Roger Bastide.

Essa orientação culturalista deixou de ser utilizada na antropologia desde fins da década de 1950. Os conceitos de aculturação, foco cultural e mudança cultural, usados nas décadas de 1940 e 1950, passaram a ser considerados como mecanicistas e inadequados a análises das relações conflitivas e da realidade colonial, que não era levada em consideração. Segundo João Leal (2016), Herskovits trabalhou com o conceito de aculturação e, a partir de meados dos anos de 1940, começou a recorrer regularmente ao conceito de sincretismo por influência de sua utilização na antropologia das religiões afro-brasileiras por Arthur Ramos desde meados da década de 1930 e por sua difusão entre outros antropólogos e folcloristas. Leal considera que foi, sobretudo, a obra de Roger Bastide que mais contribuiu para a divulgação do conceito. Analisando a antropologia brasileira, Maria José Campos (2004), comenta o esquecimento de Ramos, lembra que ele morreu cedo e não formou discípulos que dessem continuidade aos seus trabalhos. A autora diz que, após a morte, Ramos foi criticado, entre outros fatores, por ter se inspirado na teoria culturalista norte-americana. A sociologia que se desenvolveu no Brasil após a década de 1950 passou a criticar a insistência de Herskovits e seus discípulos em encontrar elementos especificamente africanos, considerando que isso acaba por dar ênfase ao que há de exótico no negro.

\section{Considerações finais}

Bem treinado em antropologia e na observação participante, como se pode constatar na correspondência com o orientador e nos trabalhos que publicou sobre o tema, Octávio da Costa Eduardo, então com 24 anos, era muito jovem quando realizou pesquisa de campo. No Maranhão, diferentemente do que ocorreu em outras regiões do país, como Salvador, Recife e Rio de Janeiro, antes da década de 1980, não havia um núcleo de pesquisas sobre o negro e as religiões afro-brasileiras. 0 acadêmico Antônio Lopes, citado por Costa Eduardo, que em 1948 organizou a Comissão de Fol- 
clore no Maranhão, foi um dos intelectuais maranhenses mais interessados no estudo sobre os negros, mas, infelizmente, morreu cedo, em 1950, e deixou poucos escritos.

Na mesma época o prematuro falecimento de Arthur Ramos, principal antropólogo brasileiro envolvido com estudos sobre o negro e as religiões afro-brasileiras, contribuiu, a nosso ver, para a redução do interesse por estudos relacionados com esses assuntos. 0 trabalho importante de Nunes Pereira sobre a Casa das Minas foi pouco divulgado e só obteve segunda edição ampliada em 1979, mais de trinta anos após sua publicação. Assim, a área de pesquisa sobre religiões afro -maranhenses continuou pouco estudada. 0 trabalho da Missão de Pesquisas Folclóricas organizada por Mário de Andrade, que realizou pesquisas no Maranhão em 1938, começou a ser divulgado em 1948, mas por muito tempo foi pouco conhecido, embora atualmente esteja mais divulgado. Nas décadas de 1950 e 1960, os estudiosos de Ciências Sociais, em sua maioria, se dedicavam a outros temas considerados mais urgentes, como as sociedades amerindias, problemas raciais ou as comunidades rurais e urbanas. As pesquisas organizadas pela Unesco no Brasil a partir de 1950 estavam mais interessadas na problemática racial e adotaram perspectiva mais sociológica do que antropológica.

A partir da década de 1950, os estudos mais destacados sobre o negro e as religiões afro-brasileiras foram realizados pelo sociólogo francês Roger Bastide. Só a partir de meados da década de 1970 seus trabalhos foram traduzidos e mais divulgados entre nós, angariando outros continuadores. Nos anos 1970, com a organização de diversos cursos de pós-graduação em sociologia e antropologia no país, esses assuntos passaram a interessar a outros pesquisadores, com a utilização de novos enfoques teóricos.
A Escola Livre de Sociologia e Política, criada em 1933 como primeiro curso de Sociologia do Brasil por iniciativa de figuras da intelectualidade paulista, estava voltada para os processos de modernização e transformação da realidade social e a formação de quadros técnicos e dirigentes empenhados na dinamização da sociedade. Com a criação do mestrado em Sociologia em 1941, a ELSP passou a formar a primeira geração de pesquisadores em Sociologia, Política e Administração e teve importância fundamental na criação de uma escola paulista de pensamento sociológico. Mas, desde a década de 1950, a liderança nessa área foi assumida principalmente pela Faculdade de Filosofia, Letras e Ciências Humanas (FFL$\mathrm{CH}$ ) da Universidade de São Paulo (USP).

A partir dos anos 1980, o tema dos estudos afro-brasileiros passou a interessar outros pesquisadores. Entretanto, o trabalho de Costa Eduardo, até hoje, é um marco essencial nesse campo. É pena que não tenha sido traduzido e que o autor não tenha podido se dedicar mais ao assunto, que foi continuado por outros que não haviam tido formação tão adequada como a dele e que não tiveram a oportunidade de contatos com a Casa das Minas em seu período de maior prestígio, sob a chefia de mãe Andresa, falecida com cerca de cem anos em 1954. 0 grupo das vodunsis gonjaís, que tinha iniciação completa, conhecido por Costa Eduardo, foi desaparecendo e terminou com a morte da última representante em 1972. A casa continuou com prestígio, sendo procurada por interessados e estudiosos, mas foi perdendo o número de participantes, até a morte, em inícios de 2015, de Dona Deni, a última vodunsi-he da Casa das Minas.

Outros grupos de tambor de mina foram se organizando no Maranhão e em 
outros locais, com novas características, incluindo maior participação masculina e aproximando-se dos cultos de umbanda e de candomblé, mais conhecidos no país. As religiões pentecostais foram se difundindo e demonizando as religiões afro-brasileiras em toda parte. Com o declínio das casas tradicionais de tambor de mina, como a Casa das Minas e a Casa de Nagô, atualmente, tem surgido o interesse pelo estudo de ritos da pajelança, do terecô e de outras formas de tambor de mina.

A Casa das Minas e a Casa de Nagô, que foram mais influentes na formação do modelo de tambor de mina do Maranhão, continuam prestigiadas, valorizadas e servindo de modelo para outros grupos atuais, mas não possuem a influência e liderança que tiveram no passado. Encontram-se, hoje, praticamente extintas, sendo conhecidas por pessoas mais antigas e por estudos como os de Costa Eduardo, que até hoje são fundamentais para o conhecimento e a análise das religiões afro-maranhenses. A divulgação de seus trabalhos é importante para o melhor conhecimento do campo religioso afro-maranhense.

\section{Referências}

AZEREDO, P. R. Antropólogos e pioneiros: a história da Sociedade Brasileira de Antropologia e Etnologia. São Paulo: FFLCH-USP, 1986.

BASTIDE, R. The Negro in Northern Brasil. Sociologia, São Paulo, v. XII, n. 3, p. 275-277, ago. 1950.

As religiões africanas no Brasil: contribuição a uma sociologia das interpenetrações de civilizações. v. 2. São Paulo: Pioneira/EDUSP, 1971. (Original 1960).

CAMPOS, M. J. Arthur Ramos, luz e sombra na antropologia brasileira: uma versão da democracia racial no Brasil nas décadas de 1930 e 1940. Rio de Janeiro: Biblioteca Nacional, 2004.
CASTRO, Y. P. Os falares africanos na interação social do Brasil Colônia. Salvador: UFBA, 1980.

DANTAS, B. G. Repensando a pureza nagô. Religião e Sociedade, Rio de Janeiro, n. 8, p. 15-20, 1982.

EDUARDO, 0. C. The Negro in Northern Brazil: a study in acculturation. New York: JJ Augustin Publisher/Monographs of the American Ethnological Society, 1948.

Aspectos do folclore numa comunidade rural. Separata de: Revista do Arquivo de São Paulo, São Paulo, v. 18, n. 144, p. 11-60, 1951.

. 0 tocador de atabaques nas casas de culto afro-maranhenses. In: Les Afro-Américains. Dakar (Senegal): IFAN, 1952. p. 119-123. Mémoires de L'Institut Français D'Afrique Noire. IFAN, $N^{\circ} 27$.

FERRETTI, S. Querebentã de Zomadonu: etnografia da Casa das Minas. 3. ed. Rio de Janeiro: Pallas, 2009.

Repensando o Sincretismo. 2. ed. São Paulo: EDUSP/ARCHÉ, 2013.

GOLDMAN, M. Os tambores dos mortos e os tambores dos vivos: etnografia, antropologia e política em Ilhéus, Bahia. Revista de Antropologia, São Paulo, v. 46, n. 2, p. 445-476, 2003.

LEAL, J. Viagens do Divino: Portugal, América do Norte e Brasil. 2016. (ms). Manuscrito ainda não publicado.

LONGEVO, E. 0 coelho e a onça: histórias brasileiras de origem africana. Ilustrações de Denise Nascimento. São Paulo: Paulinas, 2010.

LOPES, E. C. Os trabalhos de Costa Peixoto e a língua Ewe no Brasil. Lisboa: Agência Geral das Colônias, 1945. p. 40-67. Manuscrito publicado por Luis Silveira.

A propósito da Casa das Minas: Atlântico. Revista Luso-Brasileira, Lisboa, n. 5, p. 78-82, 1947. Nova Série.

Vestígios da África no Brasil. 0 mundo português. Lisboa, v. 9, n. 100, p. 109-121, mar. 1939. 
PEREIRA, N. A Casa das Minas: culto dos voduns jeje no Maranhão. 2. ed. Petrópolis, RJ: Vozes, 1979. (2ª Edição).

VERGER, P. Uma rainha africana mãe de santo em São Luís. Revista USP, São Paulo, n 6, p 151-158, ago, 1990 (Original, 1952).

\section{RESUMO}

Apresentação do problema, informações sobre a vida de Octávio da Costa Eduardo e sobre a Escola Livre de Sociologia e Política de São Paulo. Relato de pesquisas anteriores sobre religiões de origens africanas no Maranhão. Análise da correspondência de Costa Eduardo com Herskovits. Relatos sobre o trabalho de campo no $\mathrm{Ma}-$ ranhão e sobre as orientações do professor ao aluno. Comentários sobre a tese de Costa Eduardo sobre o negro no meio urbano e rural do Maranhão. Importância das pesquisas sobre negro no Maranhão e novos interesses profissionais de Costa Eduardo sobre pesquisas de mercado.

\section{PALAVRAS CHAVE}

Octávio da Costa Eduardo. Melville Herskovits. Trabalho de campo. Casa das Minas. Pesquisa sobre negro.

\section{Corrupio, 1982.}

UNESCO. Culturas Africanas. Documentos da reunião de peritos "As sobrevivências das Tradições Religiosas Africanas nas Caraibas e na América Latina”. Paris: UNESCO, 1986.

\section{ABSTRACT}

Presentation of the problem, information about Octavio da Costa Eduardo's life and about the Free School of Sociology and Politics of São Paulo. Report of previous researches about religions of African origins at Maranhão. Analysis of Costa Eduardo's correspondence with Herskovits, reports on fieldwork in Maranhão and on the guidelines from teacher to student. Comments about the Costa Eduardo's thesis on the negro in urban and rural areas of Maranhão. Importance of these researches in Maranhão and Costa Eduardo's news professionals interests on market research.

\section{KEYWORDS}

Octavio da Costa Eduardo. Melville Herskovits. Fieldwork. Casa das Minas. Research on black people. 